
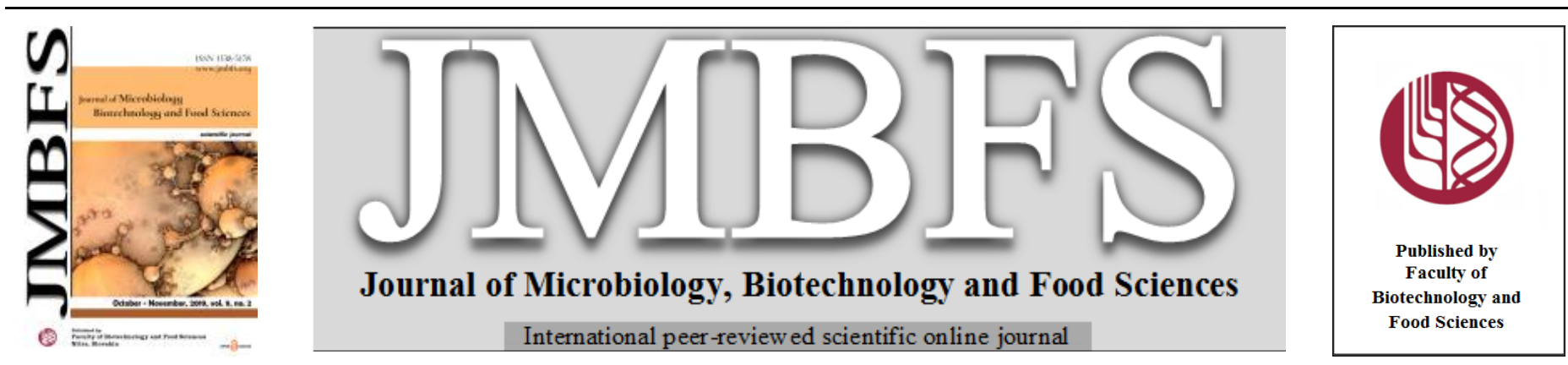

\title{
PLANT GROWTH PROMOTING ENDOPHYTIC YEAST GEOTRICHUM CANDIDUM (JX 477426) FROM ROOTS OF BRUGUIERA CYLINDRICA
}

\author{
Tijith Kuzhiyil George ${ }^{\text {; }}$; Shabanamol SubaidaBeevi ${ }^{\text {; }}$ Aju Kalarickal Asok ${ }^{l}$ and Jisha Manakulam Shaikmoideen*l
}

Address(es): Jisha Manakulam Shaikmoideen,

${ }^{1}$ School of Biosciences, Mahatma Gandhi University, P D Hills 686560, Kottayam, Kerala, Tel: +91-481-2731035 Fax-+91-481-273100, 273009, 2731011.

*Corresponding author: jishams@mgu.ac.in

doi: 10.15414/jmbfs.2019.9.2.267-272

ARTICLE INFO

Received 22. 6. 2018

Revised 16. 4. 2019

Accepted 26. 4. 2019

Published 1. 10. 2019

Regular article

open ${ }_{\text {access }}$

\begin{abstract}
Dynamic mangrove ecosystems are fascinating sources of microorganisms which serve as an extraordinary habitat for the growth and development of many endophytic microorganisms. In this study, we isolated 16 endophytic fungi thriving in the mangrove species Bruguiera cylindrica, collected from Ayiramthengu in the state of Kerala, India. All the isolated endophytes were screened for their plant growth promoting activities (IAA, siderophore and HCN production, ACC deaminase activity) and enzyme production. Among the isolates, seven displayed only a single trait from the total plant growth promoting traits evaluated, although IAA production was a common trait observed amongst the lot. When IAA concentration was quantified in the culture medium, the isolate MEF 21 showed the highest IAA production $(>45 \mu \mathrm{g} / \mathrm{mL})$. The ability of MEF 21 isolate to produce IAA, both in the presence and absence of L-Tryptophan was confirmed by TLC and GC-MS analysis. The isolate also produced siderophores and displayed ACC deaminase activity. The fungus exhibited high extracellular enzyme activity such as amylase, cellulase and protease. Vigna radiata seeds were treated with culture filtrates of MEF 21 to determine its plant growth promoting ability by vigor index method. A germination percentage of $93 \%$ and a vigor index of 337.59 were displayed by MEF 21 alone. In vitro antagonistic activity was also exhibited by MEF 21 against the plant pathogen Xanthomonas campestris with a growth inhibition zone of $35 \pm 1.5 \mathrm{~mm}$ diameter in the dual culture plate. This efficient plant growth promoting isolate, MEF 21, was further identified using morphological, biochemical and phylogenetic methods. Molecular identification included ITS-PCR utilizing universal primers. The PCR products were sequenced and submitted to GenBank. The isolate thus identified was Geotrichum candidum with an accession number JX 477426. These findings revealed the efficacy of the endophytic yeast, isolated from the surface sterilized root of the mangrove plant, to promote plant growth, development and protection.
\end{abstract}

Keywords: Biocontrol; Fungal endophytes; IAA; Mangrove; Molecular Phylogeny; Thin Layer Chromatography

\section{INTRODUCTION}

Mangrove is one of the world's most productive ecosystems with high ecological and economical significance. Mangrove plants usually exist under hostile environmental conditions such as high temperature, moisture and high salinity. They have been used in some traditional medicines and their secondary metabolites have proven for antimicrobial, antioxidant and anticancerous properties (Chaeprasert et al., 2010, Zhou et al., 2018). Endophytic microorganisms present inside the tissues of these plants are able to produce a vast array of chemical entities with multifunctional biological activities. They thrive completely or at least a part of their life cycle inside the host, without causing any visible symptoms (Aly $\boldsymbol{e t}$ al., 2011). In this mutualistic interactions, endophytes enrich the survival of host plants through different ways namely phytohormone production, enhanced nutrient uptake, antagonistic activities against plant pathogens and can also help in coping up with environmental stress conditions (Sturz et al., 2000). These synergistic interactions turn out to be beneficial for the endophytes by attaining secure ecological niche and nutrients from the host. Endophytic fungal assemblage seems more prominent than bacteria as they are labelled as the second largest ecological group of marine fungi (Sarma and Kevin 2001).

Colonization of specular endophytic fungi in a host plant primarily depends on the environmental and genetic conditions of the host plant and the endophyte (Hardoim et al., 2008). Distinctive bioactivity of an endophytic fungi greatly varies with respect to the conditions of host plant such as their location, habitat, climatic condition and the physiology of plant. All these factors influence the development and existence of many versatile endophytic fungal species in each plant and their phenotypic characters should be distinct from other naturally occurring fungal species. Hence, untapping these endophytes from extreme environmental conditions can lead to the isolation of some potential endophytic fungal species. Endophytic fungi provide inevitable support to the mangrove plant for the healthy survival and long-term succession in harsh environmental condition. Conferring with this approach, microbes inhabiting in different tissues of mangrove plants definitely have some plant growth promoting activities. Some endophytes also possess superior biosynthetic capabilities to produce certain phytochemicals which are exclusively beneficial for the host plant (Li et al., 2005). Hence, these endophytes can be utilized to biosynthesize certain treasured secondary metabolites which can ultimately trigger plant growth promotion of the host plant. (Sturz et al., 2000).

Some direct mechanisms adopted by the endophytes to enhance the plant growth and survival include induction and/or synthesis of plant growthpromoting compounds (auxins, cytokinins), synthesis of enzymes/ peptides that provide nutrient availability (phosphatases, siderophores etc), synthesis of bioactive secondary metabolites or by $\mathrm{N}_{2}$ fixation (Harman et al., 2004, Shabanamol et al., 2018). Auxins, a group of well-known plant hormones have, the ability to improve plant growth by stimulating cell elongation, root initiation, seed germination and seedling growth (El-Tarabily 2008). Indole 3 Acetic Acid (IAA) is the most abundant naturally occurring auxin compound, produced by numerous fungi and bacteria as a byproduct of the L-Tryptophan metabolism. IAA producing capability of the endophytic microorganisms and their role in plant-microbial interactions has received much attention recently. It has been reported that IAA can act as a signaling molecule between microorganisms and plant-microbe interaction for the expression of certain genes which depends on the external situations (Spaepen and Vanderleyden 2011, Fu et $\boldsymbol{a l}$., 2015). IAA also plays a vital role in the colonization and formation of mycorrhizal association on the plant roots (Mohanta and Bae 2015).

Endophytic fungi from mangroves are a relatively illimitable reservoir for bioactive metabolites. Research investigations on plant growth promoting activity of endophytic fungi associated with localized mangrove plant especially from southern coast of India are scarce. The probability to isolate certain interesting species of fungi from specialized or poorly explored habitat is very high.

Hence, the primary objective of this study was to isolate, screen and identify a potential endophytic fungus from the mangrove species Bruguiera cylindrica 
(Rhizophoraceae) based on the plant growth promoting traits. The secondary objective was to quantify and spectrally analyze the culture filtrate for IAA and to find the effect of culture filtrate on the growth of Vigna radiata seeds.

\section{MATERIALS AND METHODS}

\section{Isolation of endophytic fungi from Bruguiera cylindrica}

The collected plant materials were thoroughly washed under running tap water using tween 80 , to remove excess soil remains. Each part of the plant was handled separately for the surface-sterilization procedure, by dipping plan segments in $70 \%$ ethanol for one minute, $4 \%$ sodium hypochlorite for $45 \mathrm{sec}$, and finally $70 \%$ ethanol for one minute. Later on, these plant parts were washed thrice using sterile distilled water (Shabanamol et al., 2017). Finally rinsed sterile distilled water was streaked on a fresh PDA plate to confirm the efficiency of surface sterilization. All the steps were done under aseptic condition. The surface sterilized plant samples were cut into $1 \mathrm{~cm}$ long segments with a sterile blade and inoculated on Potato Dextrose Agar (PDA) and Yeast Extract Glucose Agar (YEGA) supplemented with streptomycin $(30 \mu \mathrm{g} / \mathrm{mL})$. The inoculated plates were incubated for 7-14 days until the fungal mycelia grew from the samples. Pure cultures of the endophytic fungi were subcultured on PDA slants and stored at $4{ }^{\circ} \mathrm{C}$ for further studies.

\section{Screening of isolates based on their plant growth promoting traits (PGP)}

\section{Phosphate solubilization}

The phosphate solubilizing ability was checked by inoculating the isolates $\left(1 \times 10^{6}\right.$ $\mathrm{CFU} / \mathrm{mL}$ ) on Pikovaskaya's agar medium and incubated for 7 days at $28 \pm 2^{\circ} \mathrm{C}$. After incubation diameter of the halo zone around the colony was measured. Phosphate solubilization on agar medium expressed in terms of solubilization efficiency (SE \%) was calculated as the ratio between the diameter of the halo zone and the diameter of the colonies.

\section{ACC deaminase production}

The ACC deaminase production of the endophytic isolate was screened using the method described by Jasim B et al., (2013) using Dworkin and Foster salts (DF) minimal medium amended with $0.2 \%$ ammonium sulphate (w/v). $20 \mu \mathrm{L}$ of the mycelial spore suspension $\left(1 \times 10^{6} \mathrm{CFU} / \mathrm{mL}\right)$ were inoculated to DF salts minimal agar medium and incubated at $28 \pm 2^{\circ} \mathrm{C}$ for two days. Positive ACC deaminase activity was determined by the growth of fungi in the medium after incubation.

\section{Siderophore production}

The qualitative detection of siderophore production by the endophytic isolates was done by the ferric chloride test (Louden et al., 2011). One $\mathrm{mL}$ of standard inoculums $\left(1 \times 10^{6} \mathrm{CFU} / \mathrm{mL}\right)$ was inoculated to $25 \mathrm{~mL}$ of King's B broth and incubated for 3 days at $28 \pm 2^{\circ} \mathrm{C}$ in a rotary shaker at $120 \mathrm{rpm}$. After incubation the inoculated broths were centrifuged at $10,000 \mathrm{rpm}$ for $10 \mathrm{~min}$. The supernatan was collected in sterile test tubes and divided in two parts. To one part, an equa volume of $2 \%$ aqueous ferric chloride solution was added and kept undisturbed for two min. Appearance of orange or red brown color indicated the presence of siderophores.

\section{Hydrocyanic acid (HCN) production test}

The production of HCN was determined by the method of Lorck (1948) with slight modifications. Fungal isolates were inoculated on potato dextrose aga medium supplemented with $4.4 \mathrm{~g}$ glycine/L. Whatman no. 1 filter paper soaked in $2 \%$ sodium carbonate in $0.5 \%$ picric acid solution was kept on the lid of the Petri plate. Plates were wrapped with parafilm and incubated for 7 days at $28^{\circ} \mathrm{C}$. After incubation, the color change of the filter paper from yellow to orange brown was considered as positive.

\section{IAA Production}

Pure cultures of the endophytic fungal isolates were screened for IAA production using the colorimetric method (Shabanamol et al., 2018). Al isolates were inoculated in PDB amended with $0.1 \%(\mathrm{w} / \mathrm{v})$ L-tryptophan and incubated at $28 \pm 2^{\circ} \mathrm{C}$ in a shaker incubator with $120 \mathrm{rpm} / \mathrm{min}$ for 7 days. Flasks with uninoculated sterile PDB broth served as control. The supernatant collected after centrifugation at $5000 \mathrm{rpm}$ for $15 \mathrm{~min}$ was mixed with Salkowski's reagen and incubated for 15-20 min. The absorbance of the solution was measured using a spectrophotometer at a wavelength of $530 \mathrm{~nm}$. IAA concentration of each isolate was compared to a standard curve.

\section{Qualitative screening of fungal enzyme activity}

All isolates were screened for the production of the extracellular enzymes such as amylases, laccases, lipases, proteases (Hankin and Anagnostakis 1975) and cellulases (Lingappa and Lockwood 1962). Production of these enzymes by the fungal endophytes was studied by digestion of suspended or dissolved substrate in agar plates after inoculation with $3 \mathrm{~mm}$ mycelial plugs, incubated for 3-5 days at $25 \pm 2^{\circ} \mathrm{C}$.

Amylase activity was assessed by growing the fungi on glucose yeast extract peptone (GYP) agar medium (glucose, $1 \mathrm{~g}$; yeast extract, $0.1 \mathrm{~g}$; peptone, $0.5 \mathrm{~g}$; agar, $16 \mathrm{~g}$; distilled water, $1000 \mathrm{~mL} ; \mathrm{pH} \mathrm{6)} \mathrm{with} 2 \%$ soluble starch. After incubation, the plates were flooded with $1 \%$ iodine in $2 \%$ potassium iodide. For cellulase, the fungi were cultured on yeast extract peptone agar medium (yeast extract, $0.1 \mathrm{~g}$; peptone $0.5 \mathrm{~g}$; agar, $16 \mathrm{~g}$ and distilled water, $1000 \mathrm{~mL}$ ) supplemented with $0.5 \%$ Na-carboxymethyl cellulose (CMC). After incubation, the plates were flooded with 0.2 aqueous Congo red and destained with $1 \mathrm{M} \mathrm{NaCl}$ for $15 \mathrm{~min}$. For lipase activity, the fungi were grown on peptone agar medium (peptone, $10 \mathrm{~g}$; $\mathrm{NaCl}, 5 \mathrm{~g}$; $\mathrm{CaCl} 22 \mathrm{H} 2 \mathrm{O}, 0.1 \mathrm{~g}$, agar, $16 \mathrm{~g}$, distilled water, 1000 $\mathrm{mL}$; pH 6) supplemented with Tween 20 (separately sterilized and added $1 \mathrm{~mL}$ to $100 \mathrm{~mL}$ medium). Protease assay was performed by growing the fungi on GYP agar medium amended with $0.4 \%$ gelatin (gelatin, $8 \mathrm{~g} / 100 \mathrm{~mL}$ distilled water sterilized separately and mixed with sterile GYP agar medium) and $\mathrm{pH}$ adjusted to 6. After incubation, plates were flooded with saturated aqueous ammonium sulphate. Laccase activity was assessed by growing the fungi on GYP agar medium amended with 1- naphthol, $0.005 \%(\mathrm{pH}, 6)$. On oxidation of 1-naphthol by laccase, the medium changed from clear to blue.

The presence of the amylase, cellulase, lipase and protease activity of the fungal isolates were checked by measuring the clear/ halo zone formed around the fungal colony on the cultured agar plates. In the case of laccase activity, positive results were inferred from a color change of the medium from clear to blue.

\section{Morphological and molecular identification of MEF 21}

The selected isolate MEF 21 showed morphological characters of yeast, so auxanographic tests were done for identification of yeast-based on their ability to assimilate carbohydrates and nitrate (Evans and Richardson 1989). The assimilation of carbohydrate was assessed using Yeast nitrogen base agar seeded with a heavy suspension of the yeast - top agar combination $(5.0 \mathrm{~mL} / 100 \mathrm{~mL}$ of media) in a Petri plate. Filter paper discs impregnated with saturated solutions of the carbohydrates (dextrose, maltose, sucrose, lactose, galactose) were placed on the surface of solidified media and incubated for $48 \mathrm{~h}$ at $25 \pm 2{ }^{\circ} \mathrm{C}$. Yeast growth around the individual discs indicated the assimilation of that particular compound. When the compound was not utilized no enhanced growth was seen. YCB (yeast carbohydrate base) media was prepared and seeded with yeast as stated above to check the nitrate assimilation. In this case, two discs, one impregnated with $\mathrm{KNO}_{3}$ and one with peptone were placed on the agar medium and incubated.

Molecular identification of the MEF 21 was done using ITS-PCR universal primers specific for fungal genomic DNA (ITS 1:5' TCCGTAGGTGAACCTGCGG-3'ITS4: 5'- TCCTCCGCTTATTGATATGC3'). The PCR product of $1.5 \mathrm{~kb}$ was purified using Illustra GFX PCR DNA and a gel band purification kit (GE Healthcare). The purified amplicon were sequenced using big dye terminator v3.2 cycle sequencing chemistry for ABI Bioprism (Applied Biosystems). The sequences were analysed using the BLAST (www.ncbi.nlm.nih.gov) search algorithm and compared with the available data in the NCBI GenBank database. The isolate sequence was deposited in the NCBI Gen Bank database. Phylogenetic relationship between the isolate and their nearest neighbours was constructed by Neighbor-joining method (Saitou and Nei 1987). The evolutionary distances were computed using the Maximum Composite Likelihood method (Tamura et al., 2004) and are in the units of the number of base substitutions per site. The analysis involved 14 nucleotide sequences, Penicillium javanicum used as the outgroup member. All positions containing gaps and missing data were eliminated. There was a total of 315 positions in the final dataset. Evolutionary analyses were conducted in MEGA7 (Kumar et al., 2016).

\section{In-vitro evaluation of antagonism effect}

The IAA producing isolates were tested for antibacterial activity using the dua culture method and disc diffusion method (Zhang et al., 2009). The potential plant pathogenic bacteria Xanthomonas campestris was selected for this study. A suspension of $24 \mathrm{hrs}$ old culture of $X$. campestris was spread on a sterile nutrien agar plate onto which a five day old disc $(5 \mathrm{~mm}$ diameter) of endophytic fungus was kept and incubated at $28 \pm 2{ }^{\circ} \mathrm{C}$ for $24-48 \mathrm{hrs}$. Antimicrobial activity was calculated by measuring the zone of inhibition produced by the endophytic fungi against the plant pathogen. 


\section{Extraction of IAA from the endophytic fungus MEF 21}

The quantification of IAA production of the selected fungus MEF 21 was done at $24 \mathrm{hrs}$ interval for seven consecutive days using the same procedure mentioned in the screening. The fungus was grown in $250 \mathrm{~mL}$ PDB (Potato Dextrose Broth) medium with and without $0.1 \%(\mathrm{w} / \mathrm{v})$ L-tryptophan. Control flasks were also maintained without inoculation. At frequent intervals of $24 \mathrm{hrs}$, the culture was filtered using Whatman no. 1 filter paper. The cell free culture filtrate was collected and analyzed for the production of IAA (Gordon and Weber 1951) The quantity of IAA in each test and control experiments was determined by plotting OD values against standard graph drawn using standard IAA.

Extraction and purification of IAA from MEF 21 was carried out according to Hinsvark et al., (1954) with minor modifications. The cell free supernatant obtained from the seven days fungus incubated PDB with and without the addition $0.1 \%$ (w/v) of L-tryptophan was first acidified to $\mathrm{pH} 3$ using $1 \mathrm{~N} \mathrm{HC}$ and then extracted with ethyl acetate (thrice). The extracts were pooled and evaporated under vacuum at $45^{\circ} \mathrm{C}$ and dissolved in $2 \mathrm{~mL}$ methanol. The $10 \mu \mathrm{L}$ extracted IAA and control IAA sample were loaded into a silica gel plate. After drying at room temperature, Thin Layer Chromatography (TLC) was developed using the solvent system of isopropanol-ammonia-distilled water $(10: 1: 1 \mathrm{v} / \mathrm{v} / \mathrm{v})$. Chromatographic chamber containing plate was kept until the solvent reached the top of the plate. The plate was completely dried at room temperature, and the plate was visualized under 360nm UV light and by Kovac's reagent sprayed on the plate. Then Rf value of both the sample and control were measured and calculated. $\mathrm{R}_{\mathrm{f}}$ value of standard IAA was compared with the $\mathrm{R}_{\mathrm{f}}$ value of sample to confirm the production of IAA.

\section{GC-MS analysis of IAA from MEF 21}

GC-MS analysis of the methanol extract of MEF 21 inoculated in tryptophan amended media and standard IAA were performed on a Perkin Elmer GC Clarus system. Varian 6000 capillary GC directly coupled to VG 70-250 mass spectrometer, using a SPB-1 fused silica capillary column. The GC injection temperature was $250^{\circ} \mathrm{C}$. The oven was programmed from $5 \mathrm{~min}$ at $80^{\circ} \mathrm{C}$ to $2400^{\circ} \mathrm{C}$ at $150 \mathrm{~min}$ and then held at $240^{\circ} \mathrm{C}$ for $30 \mathrm{~min}$. The mass spectrometer was run in the $\mathrm{EI}+$ mode at $70 \mathrm{eV}$ with the source temperature at $190^{\circ} \mathrm{C}$ and $\mathrm{GC}$ interface line heated at $260^{\circ} \mathrm{C}$. Helium at $0.07 \mathrm{MPa}$ was used as the carrier gas.

\section{Effect of MEF 21 fungal extracts on the Vigor Index of Vigna radiata seedlings}

Vigna radiata seeds were surface sterilized using $2 \% \mathrm{NaOCl}$ for $10 \mathrm{~min}$ followed by serial washing with sterile distilled water for five times. The seeds were air dried, transferred to $100 \mathrm{~mL}$ of four days old culture broth of MEF 21 supplemented with and without L-tryptophan. Control seeds were treated as same that of test sample without the fungal inoculation. Seeds were then incubated for $24 \mathrm{hrs}$ in a rotary shaker at $120 \mathrm{rpm}$ and $28 \pm 2{ }^{\circ} \mathrm{C}$ (Chandrashekhara. et al., 2007).

After incubation, 20 seeds from each flask were randomly selected and placed aseptically in Petri plates with sterile moistened filter paper. All the plates were set for germination under dark at $28 \pm 2^{\circ} \mathrm{C}$ for seven days. The number of germinated seeds and shoot and root lengths of the seedlings were measured Seedling vigor index was calculated using the formula.

Vigor Index $=($ Mean root length + shoot length $)$ Germination percentage

\section{Statistical Analysis}

Results are expressed as mean values \pm standard deviation $(\mathrm{n}=3)$. Data were analyzed with one-way ANOVA. Differences were considered significant when $\mathrm{p}<0.05$

\section{RESULTS AND DISCUSSION}

\section{Isolation and screening of endophytic fungi}

A total of 16 macroscopically and microscopically different endophytic fungal isolates were obtained from leaves and root of Bruguiera cylindrica. Nine isolates from leaf (MEF1, MEF 4, MEF 5, MEF 6, MEF 7, MEF 11, MEF 13 , MEF 14 and MEF 20) and seven isolates from roots (MEF 2, MEF 12, MEF 17, MEF 18, MEF 21, MEF 22 and MEF 23) were obtained. The isolation of endophytic fungi revealed that, the occurrence of endophytes varied in differen parts of the plant and extent arbitrarily depending on the environmenta conditions. All the isolates were further screened for their plant growth promoting traits.

Among the 16 endophytic fungal isolates, seven of them demonstrated only a single trait from the total plant growth promoting traits evaluated (Tab 1). None of the isolates possessed HCN production ability. The isolate MEF 21 showed positive reaction for ACC deaminase activity and siderophore production. However, this fungal isolate was unable to solubilize phosphate. Only six among the 16 isolates were found to produce IAA in the culture broth containing Ltryptophan. Among these, MEF 21 had the highest IAA production $(45 \mu \mathrm{g} / \mathrm{mL})$ and was selected for further quantification and extraction of IAA. All other isolates produced IAA $\leq 10 \mu \mathrm{g} / \mathrm{mL}$

Table 1 Plant growth promoting activities of the Bruguiera cylindrica endophytic fungal isolates tested

\begin{tabular}{|c|c|c|c|c|c|}
\hline Isolates & $\begin{array}{l}\text { Siderophore } \\
\text { production }\end{array}$ & $\begin{array}{l}\text { Phosphate } \\
\text { solubilisation }\end{array}$ & $\begin{array}{c}\text { Hydrocyanic acid } \\
\text { (HCN) production test }\end{array}$ & $\begin{array}{c}\text { ACC deaminase } \\
\text { production }\end{array}$ & $\begin{array}{l}\text { IAA production } \\
(\mu \mathrm{g} / \mathrm{mL})\end{array}$ \\
\hline MEF 1 & - & - & - & - & - \\
\hline MEF 2 & - & ++ & - & - & 5 \\
\hline MEF 4 & - & - & - & - & - \\
\hline MEF 5 & - & - & - & - & - \\
\hline MEF 6 & - & - & - & - & - \\
\hline MEF 7 & - & - & - & - & 10 \\
\hline MEF 11 & - & - & - & - & - \\
\hline MEF 12 & - & + & - & - & - \\
\hline MEF 13 & - & - & - & - & - \\
\hline MEF 14 & - & - & - & - & 8 \\
\hline MEF 17 & - & - & - & - & 10 \\
\hline MEF 18 & - & - & - & - & - \\
\hline MEF 20 & - & - & - & - & - \\
\hline MEF 21 & ++ & - & - & + & 45 \\
\hline MEF 22 & - & - & - & - & - \\
\hline MEF 23 & - & - & - & - & 10 \\
\hline
\end{tabular}

\section{Qualitative screening of fungal enzyme activity}

Mangrove endophytic fungi serves as a potential source of cell wall degrading / hydrolytic enzymes, such as chitinase, protease, cellulase, etc (Govinda Rajulu et al., 2011, Behera et al., 2017). These enzymes may contribute to the antagonistic activity against plant pathogenic fungi/bacteria (Marco et al., 2003). As an outcome, host plant growth will be enhanced by the presence of these fungi. Assay of fungal cell wall-degrading enzymes indicated that the isolate MEF 7 produced all the tested enzymes (amylase, cellulose, laccase, lipase and protease) (Tab 2). Seven of the isolates demonstrated significant zone of clearance in starch agar, indicating their ability to produce amylase. Besides these, four isolates showed significant protease production. Four of the isolated endophytes produced cellulase. Most of the soil fungi produce lignocellulose modifying exoenzymes like laccase (Pundir et al., 2016). In this study, six of the isolates showed laccase activity, suggesting their involvement in the litter degradation processes. Only two fungal isolates showed lipase activity, which indicate they have the ability to utilize fat as their energy source. If the endophytes are capable of producing extracellular enzymes, they can act as biocontrol agents. 
Table 2 In vitro enzyme activity of mangrove plant Bruguiera cylindrica endophytic fungal isolates

\begin{tabular}{lccccc}
\hline Isolates code & Amylase & Cellulase & Laccase & Lipase & Protease \\
\hline MEF 1 & - & \pm & + & - & - \\
\hline MEF 2 & - & \pm & $+(2.2 \mathrm{~cm})$ & - & \pm \\
\hline MEF 4 & $+(3 \mathrm{~cm})$ & \pm & - & - & \pm \\
\hline MEF 5 & - & - & - & - & - \\
\hline MEF 6 & - & - & - & - & \pm \\
\hline MEF 7 & $+(2 \mathrm{~cm})$ & $+(1 \mathrm{~cm})$ & $+(1.6 \mathrm{~cm})$ & $+(2 \mathrm{~cm})$ & $+(1.6 \mathrm{~cm})$ \\
\hline MEF 11 & \pm & \pm & $+(1.5 \mathrm{~cm})$ & - & - \\
\hline MEF 12 & \pm & - & \pm & - & - \\
\hline MEF 13 & \pm & - & $+(1 \mathrm{~cm})$ & - & $+(2.3 \mathrm{~cm})$ \\
\hline MEF 14 & - & - & - & - & - \\
\hline MEF 17 & $+(0.6 \mathrm{~cm})$ & - & - & - & \pm \\
\hline MEF 18 & $+(1 \mathrm{~cm})$ & $+(2 \mathrm{~cm})$ & $+(1 \mathrm{~cm})$ & - & - \\
\hline MEF 20 & $+(1.9 \mathrm{~cm})$ & $+(1.8 \mathrm{~cm})$ & - & - & \pm \\
\hline MEF 21 & $+(2,2 \mathrm{~cm})$ & $+(2.7 \mathrm{~cm})$ & - & - & $+(1.7 \mathrm{~cm})$ \\
\hline MEF 22 & $+(2 \mathrm{~cm})$ & - & - & $+(2 \mathrm{~cm})$ & + \\
\hline MEF 23 & \pm & - & $+(2.7 \mathrm{~cm})$ & - & $+(2.5 \mathrm{~cm})$ \\
\hline+ PESive & + & - & &
\end{tabular}

+ positive, -negative and \pm may be positive

\section{Morphological and molecular identification of MEF 21}

Auxanographic test revealed that the isolate was able to utilize glucose and galactose only and was unable to assimilate nitrate. From these findings MEF 21 was identified as Geotrichum sp. Molecular identification of MEF 21 revealed its identity as Geotrichum candidum with the accession number JX477426. The isolate sequence was compared with the ITS sequences of other related organisms as shown in Figure 1. The endophytic isolate MEF 21 showed higher relation to Geotrichum candidum and Galactomyces candidum formed on sister clade.

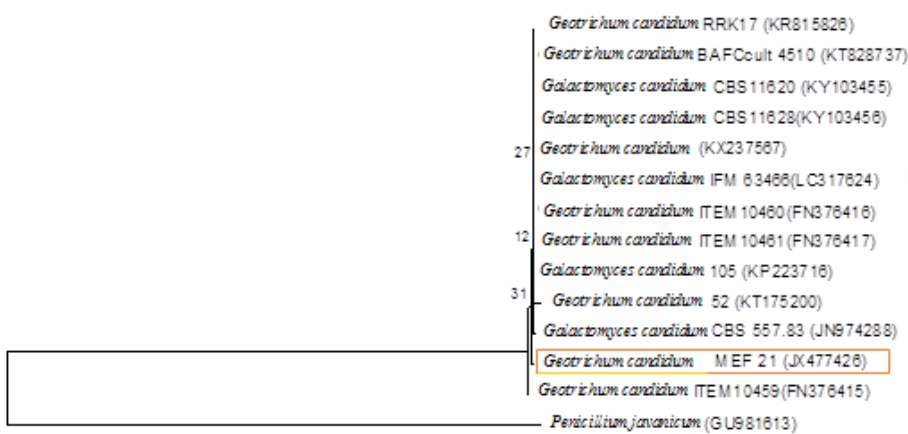

Figure 1 Neighbor-joining tree of fungal endophyte sp. Geotrichum candidum MEF 21 (JX477426) with related fungi based on 18S rDNA ITS sequences. Numbers at branch nodes refer to bootstrap values (1,000 replicates). Penicillium javanicum was chosen as outgroup in the phylogenies. The bar indicates a $5 \%$ sequence divergence.

\section{Detection of antagonistic activity}

MEF 21 showed an eloquent zone of inhibition against the plant pathogen Xanthomonas campestris in the in vitro dual culture with $35 \pm 1.5 \mathrm{~mm}$ diameter when compared to control (Figure 2). It has been reported that different mechanisms namely competition for space and nutrients, secretion of chitinolytic enzymes, mycoparasitism and production of inhibitory compounds are responsible for biocontrol activity of these endophytic fungi (Roco and Pérez 2001)

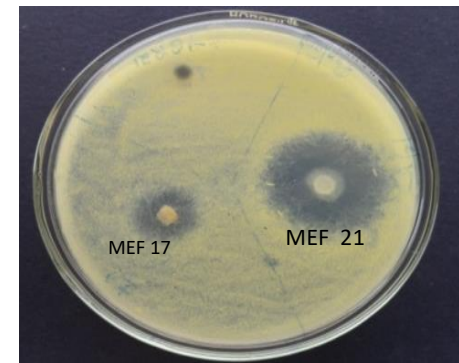

Figure 2 Antagonistic activity of the isolate MEF 21 against the plant pathogen Xanthomonas campestris

\section{Quantification and extraction of IAA from MEF 21}

G. candidum can produce higher amount of IAA in the culture medium in the presence of L-tryptophan than in the absence of L-tryptophan. In the quantification assay, the isolate was able to produce an amount of more than 45 $\mu \mathrm{g} / \mathrm{mL}$ (Figure $3 \mathrm{a}$ ) of IAA within the first four days of incubation in the PDB media amended with tryptophan. While filtrate from PDB without L-tryptophan showed only a mild IAA production.

The TLC plates showed similar $R_{f}$ values $\left(0.5 R_{f}\right)$ for Standard IAA and extracted IAA under UV light at $254 \mathrm{~nm}$ (Figure $3 \mathrm{~b}$ ). The test band was scraped out and GC-MS was performed for further confirmation.
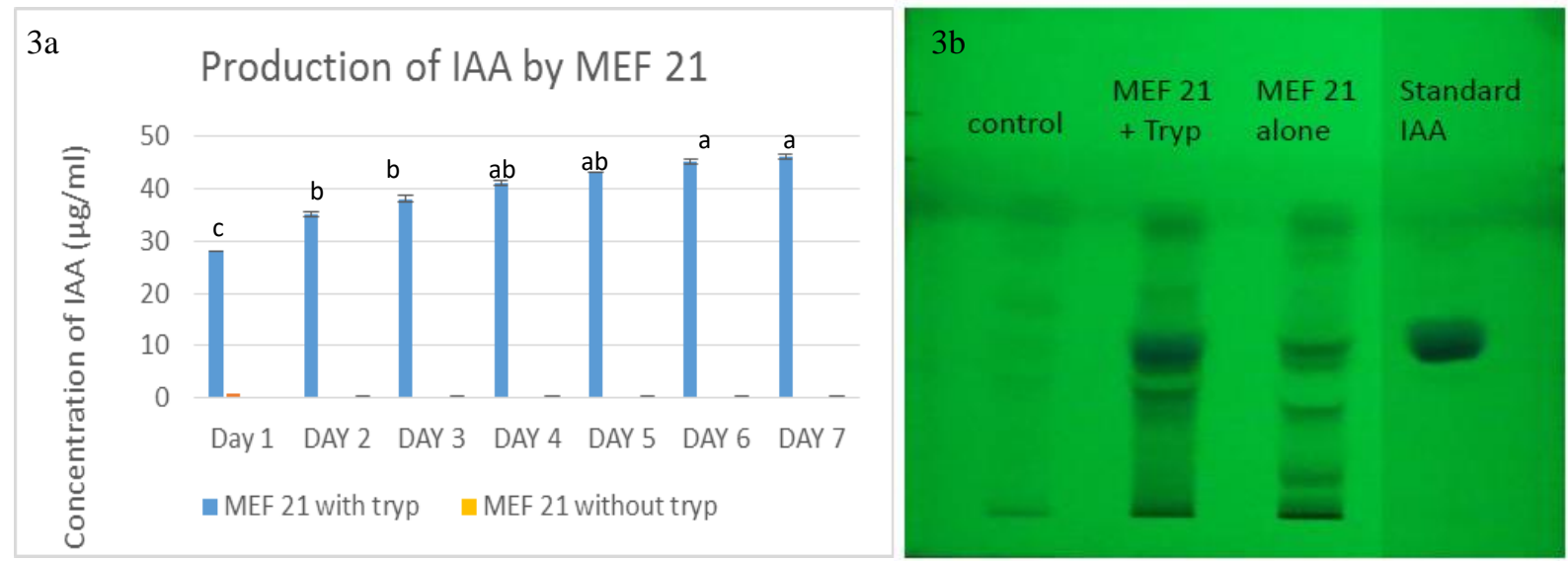

Figure 3a Quantitative estimation of IAA spectrophotometrically at 530nm for 7 days, means with same letters are not significantly different, CD $(0.05)=0.017$, Figure 3b. TLC analysis of IAA in the culture filtrate of MEF 21

A general gas chromatography mass spectrometric identification of the indole-3acetic acid (IAA) in the culture filtrate of MEF 21 revealed the presence of IAA in the culture filtrate with respect to the standard IAA. GC-MS analysis of standard IAA showed a peak at RT $10.7 \mathrm{~min}$ corresponding to IAA and respective peaks in the test spectrum analysis also. Mass spectrometric analysis of the standard IAA and the test were also found to be similar (Figure 4). The peak at 10.783 gave the mass fragments of IAA, m/z 175 corresponds to IAA and $\mathrm{m} / \mathrm{z} 130$ corresponds to a fragment of IAA i.e $\mathrm{C}_{9} \mathrm{H}_{8} \mathrm{~N}$. The spectrum data confirms the IAA producing ability of MEF 21 in the presence/ in the absence of L-tryptophan. 

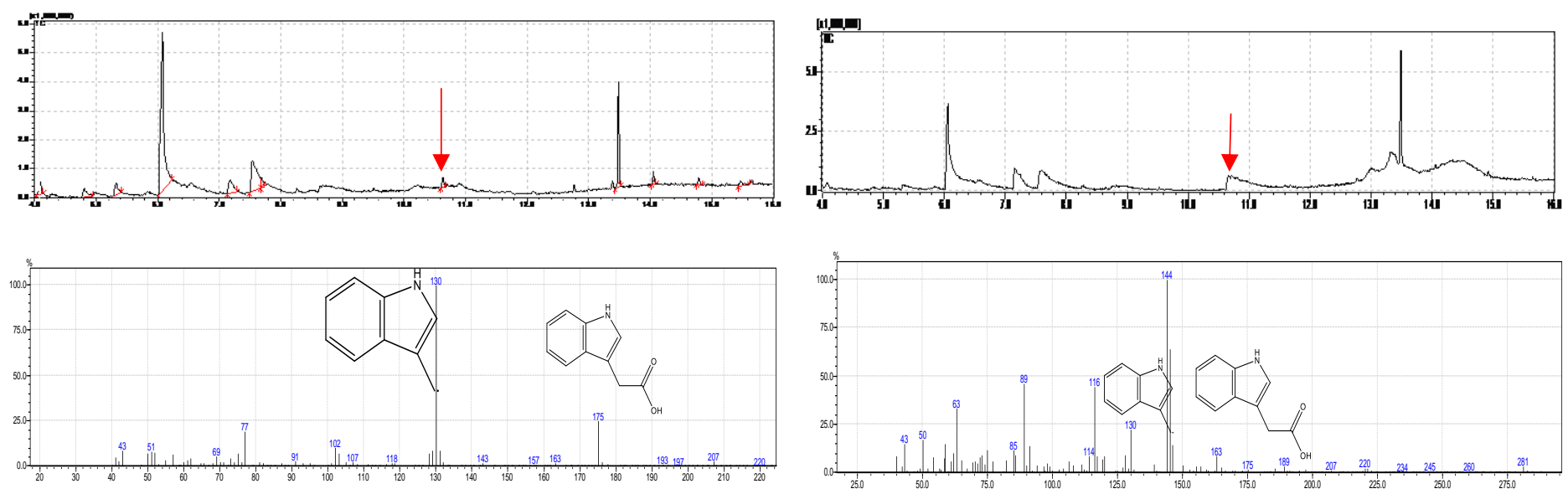

Figure 4 Gas chromatographic Mass spectrum analysis of IAA in the extract MEF21 cultured broth , first lane Gas chromatographic analysis of MEF 21 culture filtrate supplimented with tryptophan and without tryptophan respectively, second lane is the mass spectrum of corresponding chromatogram showing peaks at retention times $10.7 \mathrm{~min}$. Both mass spectrum shows the presence of methyl indole (m/z 130) and IAA (m/z 175)

Effect of the endophytic MEF 21 fungal extract on the Vigor Index of Vigna radiata seedlings

germination percentage (93\%) as compared to those from the seeds treated with the uninoculated control broth. Meanwhile, culture filtrate incorporated with Ltryptophan showed an enhanced germination percentage (96\%) (Figure 5). Vigor index of the seedlings was found to be 583.68 for G. candidum (MEF21) supplemented with tryptophan, 337.59 for $G$. candidum and 129.48 for

IAA producing fungi/ bacteria can increase the plant growth by stimulating the number of root hairs and lateral root formation. These organisms can also increase the percentage of seed germination. In this study Vigna radiata seeds uninoculated (control) seeds (Tab 3) treated with culture filtrates of MEF 21 showed statistically significant

Table 3 The vigor index of Vigna radiata inoculated with the endophytic yeast Geotrichum candidum (MEF 21)

\begin{tabular}{|c|c|c|c|c|}
\hline No. & Treatment & $\begin{array}{c}\text { Seedling total length in cm } \\
\text { (Mean root length+ Mean shoot } \\
\text { length) }\end{array}$ & $\begin{array}{c}\text { Germination } \\
\text { percentage }\end{array}$ & Vigor Index (VI) \\
\hline 1 & Control & $1.56 \pm 0.005$ & $83 \%$ & 129.48 \\
\hline 2 & $\begin{array}{l}\text { MEF } 21 \\
\text { alone }\end{array}$ & $3.63 \pm 0.01 *$ & $93 \% *$ & 337.59 \\
\hline 3 & $\begin{array}{l}\text { MEF } 21+ \\
\text { Tryptophan }\end{array}$ & $6.08 \pm 0.01 *$ & $96 \% *$ & 583.68 \\
\hline
\end{tabular}

Effect of Geotrichum candidum on root length and shoot length expressed as mean $\pm \mathrm{SD}(n=3)$, asterisk $(*)$ represents significant difference between treatments and control, $P<0.05$.

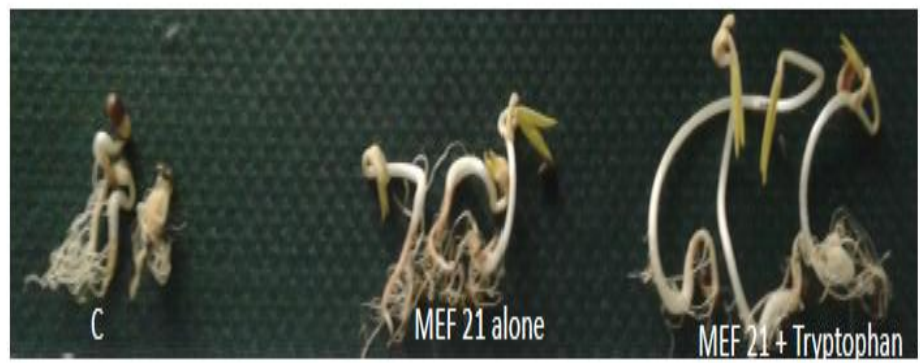

Figure 5 Enhanced vigor index of Vigna radiata seedlings treated with Geotrichum candidum (MEF 21).

On the contrary, G. candidum (MEF21) showed higher in vitro plant growth promotion ability than the control treatment in the presence and absence of tryptophan. This indicated that the isolate MEF 21 uses both tryptophan dependent and the Try independent pathway for IAA production. In the absence of tryptophan MEF 21 may have been capable of obtaining the precursor from the host plant or it may follow an alternative pathway for the IAA synthesis. The physiological role of auxin in fungi other than root elongation is not well understood. One of the roles suggested for fungal IAA is to mediate fungal-plant interaction thereby favoring the transfer of phytohormones from plant system to soil and vice versa (Fu et al., 2015). IAA-producing PGPR are believed to increase root growth and root length, resulting in greater root surface area which enables the plant to access more nutrients from soil. The effect of $G$. candidum culture filtrate treated seeds were observable on the shoot and root elongation of the seedlings without showing any disease symptoms on the inoculated plants. It may be attributed by the activity of plant growth promoting secondary metabolites (IAA) from fungal culture filtrates. These results suggest that the isolated strain is safe for field application.
The IAA producing ability of endophytic bacteria (Jasim B et al.,. 2013), filamentous fungi (Le Floch et al.,. 2003) and yeasts (Nassar et al., 2005) were reported for their plant growth promoting activity in the in vitro condition. The endophytic yeast Williopsis saturnus was reported to promote the growth of maize and Beta vulgaris L. (sugar beet) by producing plant auxins, such as indole-3-acetic acid (IAA) and indole-3-pyruvic acid (IPYA) (Nassar $\boldsymbol{e t}$ al., 2005). The endophytic bacteria Gluconacetobacter diazotrophicus was reported to produce auxin in chemically defined medium in the absence of L-TRP and also showed potential beneficial effects on the plant growth. Genes involved in the biosynthesis of IAA in G. diazotrophicus PAL5 was also determined (Rodrigues et al. 2016). Rao et al., (2010) has given an account of IAA production in the absence of L-TRP by some yeasts. Applications of IAA producing yeasts, such as Saccharomyces roseus, Candida valida, Rhodotorula glutinis, $R$ mucilaginosa, and Lindera (Williopsis) saturnus for the plant growth promotion have been described by (Nassar $\boldsymbol{e t}$ al., 2005), but the observable applications of G. candidum on the growth promotion of Vigna seedlings has not been reported. Hence, G. candidum can be considered as a novel endophytic fungi which can promote plant growth and development of Vigna radiata.

G. candidum has the ability to produce high antimicrobial compound and IAA. In fact reports from Spaepen and Vanderleyden (2011) have stated that most of the plant pathogenic bacteria and fungi are characterized by increased IAA production as a part of their pathogenicity. However, in this study it is clear that the isolate MEF 21 is not associated to plant pathogenicity. The yeast Torulaspora globosa has been shown to be antagonistic towards the phytopathogenic mold Colletotrichum sublineolum, even though it is negative for siderophores, volatile compounds or fungal wall hydrolytic enzyme production (Rosa et al., 2010). The present study also depicted concurrent results as the isolate did not produce any VOCs or $\mathrm{HCN}$ and thus the exact mechanism of biocontrol couldn't be elucidated. Therefore, a more detailed investigation is required to demonstrate the potential of these organisms for the biocontrol of pathogenic bacteria and plant growth promotion which may be useful in pharmacological and agricultural fields in the future.

\section{CONCLUSION}

Mangrove plants can be explored for the discovery of exclusive and multifunctional endophytic fungi. Sixteen endophytic fungi were isolated from the mangrove plant Bruguiera cylindrica. Preliminary studies on plant growth 
promoting traits of endophytic isolates revealed the identification of a fast growing IAA producing endophytic yeast Geotrichum candidum MEF 21. The isolate displayed significant IAA production in the culture media without the addition of L-TRP, thereby promoting the growth of Vigna radiata seedlings. The isolate also showed in vitro antagonistic activity against Xanthomonas campestris. A better understanding of this versatile endophytic yeast may help to elucidate its significance and potential role in the field of sustainable agriculture.

Acknowledgement: The authors are grateful to Kerala State Council for Science, Technology and Environment for the funding [026/FSHP-LSS/2013/KSCSTE] and DBT-MSUB Project for the instrumentation facility.

Conflict of interest: The authors do not have any conflict of interest in the publication of this paper.

\section{REFERENCE}

Aly AH, Debbab A, Proksch P (2011) Fungal endophytes: unique plant inhabitants with great promises. Appl Microbiol Biotechnol 90:1829-1845. http://dx.doi.org/10.1007/s00253-011-3270-y

Behera BC, Sethi BK, Mishra RR, et al (2017) Microbial cellulases - Diversity \&amp; biotechnology with reference to mangrove environment: A review. J Genet Eng Biotechnol 15:197-210. http://dx.doi.org/10.1016/J.JGEB.2016.12.001

Chaeprasert S, Piapukiew J, Whalley AJS, Sihanonth P (2010) Endophytic fungi from mangrove plant species of Thailand: their antimicrobial and anticancer potentials. Bot Mar 53:555-564. http://dx.doi.org/10.1515/bot.2010.074

Chandrashekhara., Niranjanra S, Deepak SA, et al (2007) Endophytic Bacteria from Different Plant Origin Enhance Growth and Induce Downy Mildew Resistance in Pearl Millet. Asian J Plant Pathol 1:1-11. http://dx.doi.org/10.3923/ajppaj.2007.1.11

E. G. V. Evans, M. D. Richardson (1989) Medical mycology a practical approach edited by E. G. V. Evans, M. D. Richardson | Aspergillus \&amp; Aspergillosis Website. Oxford IRL Press 1989

El-Tarabily KA (2008) Promotion of tomato (Lycopersicon esculentum Mill.) plant growth by rhizosphere competent 1-aminocyclopropane-1-carboxylic acid deaminase-producing streptomycete actinomycetes. Plant Soil 308:161-174. http://dx.doi.org/10.1007/s11104-008-9616-2

Fu S-F, Wei J-Y, Chen H-W, et al (2015) Indole-3-acetic acid: A widespread physiological code in interactions of fungi with other organisms. Plant Signal Behav 10:e1048052. http://dx.doi.org/10.1080/15592324.2015.1048052 Gordon SA, Weber RP (1951) COLORIMETRIC ESTIMATION OF INDOLEACETIC ACID. Plant Physiol 26:192-5

Govinda Rajulu MB, Thirunavukkarasu N, Suryanarayanan TS, et al (2011) Chitinolytic enzymes from endophytic fungi. Fungal Divers 47:43-53. http://dx.doi.org/10.1007/s13225-010-0071-z

Hankin L, Anagnostakis SL (1975) The Use of Solid Media for Detection of Enzyme Production by Fungi. Mycologia 67:597. http://dx.doi.org/10.2307/3758395

Hardoim PR, van Overbeek LS, Elsas JD van (2008) Properties of bacterial endophytes and their proposed role in plant growth. Trends Microbiol 16:463471. http://dx.doi.org/10.1016/j.tim.2008.07.008

Harman GE, Howell CR, Viterbo A, et al (2004) Trichoderma species opportunistic, avirulent plant symbionts. Nat Rev Microbiol 2:43-56 http://dx.doi.org/10.1038/nrmicro797

Hinsvark ON, Houff WH, Wittwer SH, Sell HM (1954) The Extraction and Colorimetric Estimation of Indole-3-Acetic Acid and Its Esters in Developing Corn Kernels. Plant Physiol 29:107-8

Jasim B, Jimtha C. John, Jyothis Mathew, Radhakrishnan EK (2013) Plan growth promoting potential of endophytic bacteria isolated from Piper nigrum. Plant Growth Regul 71:1-11

Kumar S, Stecher G, Tamura K (2016) MEGA7: Molecular Evolutionary Genetics Analysis Version 7.0 for Bigger Datasets. Mol Biol Evol 33:1870-1874 http://dx.doi.org/10.1093/molbev/msw054

Le Floch G, Rey P, Benizri E, et al (2003) Impact of auxin-compounds produced by the antagonistic fungus Pythium oligandrum or the minor pathogen Pythium group F on plant growth. Plant Soil 257:459-470. http://dx.doi.org/10.1023/A:1027330024834

Li H, Qing C, Zhang Y, Zhao Z (2005) Screening for Endophytic Fungi with Antitumour and Antifungal Activities from Chinese Medicinal Plants. World J Microbiol Biotechnol 21:1515-1519. http://dx.doi.org/10.1007/s11274-0057381-4

Lingappa Y, Lockwood JL (1962) Chitin media for selective isolation and culture of actinomycetes. Phytopathology 52:317-323

Lorck H (1948) Production of Hydrocyanic Acid by Bacteria. Physiol Plant 1:142-146. http://dx.doi.org/10.1111/j.1399-3054.1948.tb07118.x

Louden BC, Haarmann D, Lynne AM (2011) Use of Blue Agar CAS Assay for Siderophore Detection. J Microbiol Biol Educ 12:51-3. http://dx.doi.org/ $10.1128 /$ jmbe.v12i1.249

Marco JL De, Valadares-Inglis MC, Felix CR (2003) Production of hydrolytic enzymes by Trichoderma isolates with antagonistic activity against Crinipellis perniciosa, the causal agent of witches' broom of cocoa. Brazilian J Microbiol 34:33-38. http://dx.doi.org/10.1590/S1517-83822003000100008

Mohanta TK, Bae H (2015) Functional genomics and signaling events in mycorrhizal symbiosis. J Plant Interact 10:21-40. http://dx.doi.org/10.1080/17429145.2015.1005180

Nassar AH, El-Tarabily KA, Sivasithamparam K (2005) Promotion of plant growth by an auxin-producing isolate of the yeast Williopsis saturnus endophytic in maize (Zea mays L.) roots. Biol Fertil Soils 42:97-108 http://dx.doi.org/10.1007/s00374-005-0008-y

Pundir RK, Mishra VK, Rana S, Lakhani M (2016) Screening of Laccase producing fungi from soil samples - An In Vitro Study. Electron J Biol 12:

Rao RP, Hunter A, Kashpur O, Normanly J (2010) Aberrant Synthesis of Indole3-Acetic Acid in Saccharomyces cerevisiae Triggers Morphogenic Transition, a Virulence Trait of Pathogenic Fungi. Genetics 185:211-220. http://dx.doi.org/10.1534/genetics.109.112854

Roco A, Pérez LM (2001) In vitro biocontrol activity of Trichoderma harzianum on Alternaria alternata in the presence of growth regulators. Electron J Biotechnol 4:0-0. http://dx.doi.org/ 10.2225/vol4-issue2-fulltext-1

Rodrigues EP, Soares C de P, Galvão PG, et al (2016) Identification of Genes Involved in Indole-3-Acetic Acid Biosynthesis by Gluconacetobacter diazotrophicus PAL5 Strain Using Transposon Mutagenesis. Front Microbiol 7:1572. http://dx.doi.org/10.3389/fmicb.2016.01572

Rosa MM, Tauk-Tornisielo SM, Rampazzo PE, Ceccato-Antonini SR (2010) Evaluation of the biological control by the yeast Torulaspora globosa against Colletotrichum sublineolum in sorghum. World J Microbiol Biotechnol 26:14911502. http://dx.doi.org/10.1007/s11274-010-0324-8

Saitou N, Nei M (1987) The neighbor-joining method: a new method for reconstructing phylogenetic trees. Mol Biol Evol 4:406-25

Sarma V v, Kevin DH (2001) A review on frequently occurring fungi in mangroves. Fungal Divers 8:1-34

Shabanamol S, Divya K, George TK, et al (2018) Characterization and in planta nitrogen fixation of plant growth promoting endophytic diazotrophic Lysinibacillus sphaericus isolated from rice ( Oryza sativa ). Physiol Mol Plan Pathol 102:46-54. http://dx.doi.org/10.1016/j.pmpp.2017.11.003

Shabanamol S, Sreekumar J, Jisha MS (2017) Bioprospecting endophytic diazotrophic Lysinibacillus sphaericus as biocontrol agents of rice sheath blight disease. 3 Biotech 7:337. http://dx.doi.org/10.1007/s13205-017-0956-6

Spaepen S, Vanderleyden J (2011) Auxin and Plant-Microbe Interactions. Cold Spring Harb Perspect Biol 3:a001438-a001438 http://dx.doi.org/10.1101/cshperspect.a001438

Sturz A V., Christie BR, Nowak J (2000) Bacterial Endophytes: Potential Role in Developing Sustainable Systems of Crop Production. CRC Crit Rev Plant Sci 19:1-30. http://dx.doi.org/10.1080/07352680091139169

Tamura K, Nei M, Kumar S (2004) Prospects for inferring very large phylogenies by using the neighbor-joining method. Proc Natl Acad Sci 101:11030-11035 http://dx.doi.org/10.1073/pnas.0404206101

Zhang Y, Mu J, Feng Y, et al (2009) Broad-spectrum antimicrobial epiphytic and endophytic fungi from marine organisms: isolation, bioassay and taxonomy. Mar Drugs 7:97-112. http://dx.doi.org/10.3390/md7020097

Zhou J, Diao X, Wang T, et al (2018) Phylogenetic diversity and antioxidant activities of culturable fungal endophytes associated with the mangrove species Rhizophora stylosa and R. mucronata in the South China Sea. PLoS One 13:e0197359. http://dx.doi.org/10.1371/journal.pone.0197359 